\title{
Review
}

\section{The systems medicine of cannabinoids in pediatrics: the case for more pediatric studies}

\author{
Chloe P. O’Dell ${ }^{1, \dagger}$, Dawn S. Tuell ${ }^{1, \dagger}$, Darshan S. Shah ${ }^{1, \dagger}$, William L. Stone ${ }^{1, *}$ \\ ${ }^{1}$ Department of Pediatrics, James H. Quillen College of Medicine, East Tennessee State University, Johnson City, TN 37614, USA \\ *Correspondence: stone@etsu.edu (William L. Stone) \\ ${ }^{\dagger}$ These authors contributed equally. \\ Academic Editor: Graham Pawelec \\ Submitted: 8 September 2021 Revised: 15 November 2021 Accepted: 1 December 2021 Published: 11 January 2022
}

\begin{abstract}
Introduction: The legal and illicit use of cannabinoid-containing products is accelerating worldwide and is accompanied by increasing abuse problems. Due to legal issues, the USA will be entering a period of rapidly expanding recreational use of cannabinoids without the benefit of needed basic or clinical research. Most clinical cannabinoid research is focused on adults. However, the pediatric population is particularly vulnerable since the central nervous system is still undergoing developmental changes and is potentially susceptible to cannabinoid-induced alterations. Research design and methods: This review focuses on the systems medicine of cannabinoids with emphasis on the need for future studies to include pediatric populations and mother-infant dyads. Results and conclusion: Systems medicine integrates omics-derived data with traditional clinical medicine with the long-term goal of optimizing individualized patient care and providing proactive medical advice. Omics refers to large-scale data sets primarily derived from genomics, epigenomics, proteomics, and metabolomics.
\end{abstract}

Keywords: Cannabinoids; Cannabis; Marijuana; Systems medicine; Omics; Pediatrics; Review

\section{Introduction}

As more countries and states in the USA legalize medical or recreational marijuana, there will be both foreseen and unforeseen consequences relevant to pediatrics. The pediatric health care community should ensure that adequate resources are made available in an overall attempt to minimize harm in the face of the coming tsunami of marijuana/cannabinoid exposure to pediatric patients. Daily and weekly use of marijuana during pregnancy have markedly increased over the last decade [1]. Moreover, recent data shows a marked increase in the number of teenagers vaping marijuana [2]. Nicotine vaping (e-cigarettes) in adolescents and young adults is associated with a significant rise in coronavirus 2019 (COVID-19) diagnosis [3]. The potential association of cannabinoid oil vaping with COVID-19 signs has not been well studied. Noteworthy is a report indicating that USA states that have legalized recreational marijuana use show fewer cases of e-cigarette/vaping lung injury cases than states without such legalization [4]. A primary goal of this review is to outline how a systems medicine/biology approach could improve our understanding of how exposure to cannabinoids (CBs) could affect fetal development during pregnancy and affect adolescents [5]. Moreover, this approach holds the potential of optimizing individualized patient care and providing proactive medical advice. For the sake of brevity, we will generally provide internet links or references with clear definitions of technical terms and relevant background summaries. Hopefully, this will enable both basic scientists and general healthcare providers to benefit from this review. We will also point out research gaps pertinent to pediatrics and identify potential pediatric health care delivery system stressors.

Cannabinoid effects on brain development during fetal/neonatal development are well documented and highlight the need to emphasize continued and expanded studies on this population [6]. Less appreciated, however, is the fact that brain development does not stop until late adolescence (18-24 years old) [7,8]. After alcohol, marijuana is the most commonly used substance, and its use has increased in the past decade for students in 12th grade [9].

There have been, and there remain, significant barriers in cannabis and cannabinoid research, including the classification of cannabis as a Schedule I substance under federal law [10]. However, the USA House of Representatives has passed a bill (2020) that will decriminalize marijuana and remove it from the Controlled Substances Act. Nevertheless, we will be entering a period of rapidly expanding recreational use of cannabis and cannabinoids without the benefit of an appropriately extensive base of either basic or clinical research. Moreover, the brain has arguably been termed "the most complex biological system in nature", and our understanding of how cannabinoids affect this system is still in its infancy [11]. A systems medicine approach to cannabinoid research may prove helpful in capturing this intrinsic complexity and translating such information into clinically meaningful information and evidence-based policies [12]. 


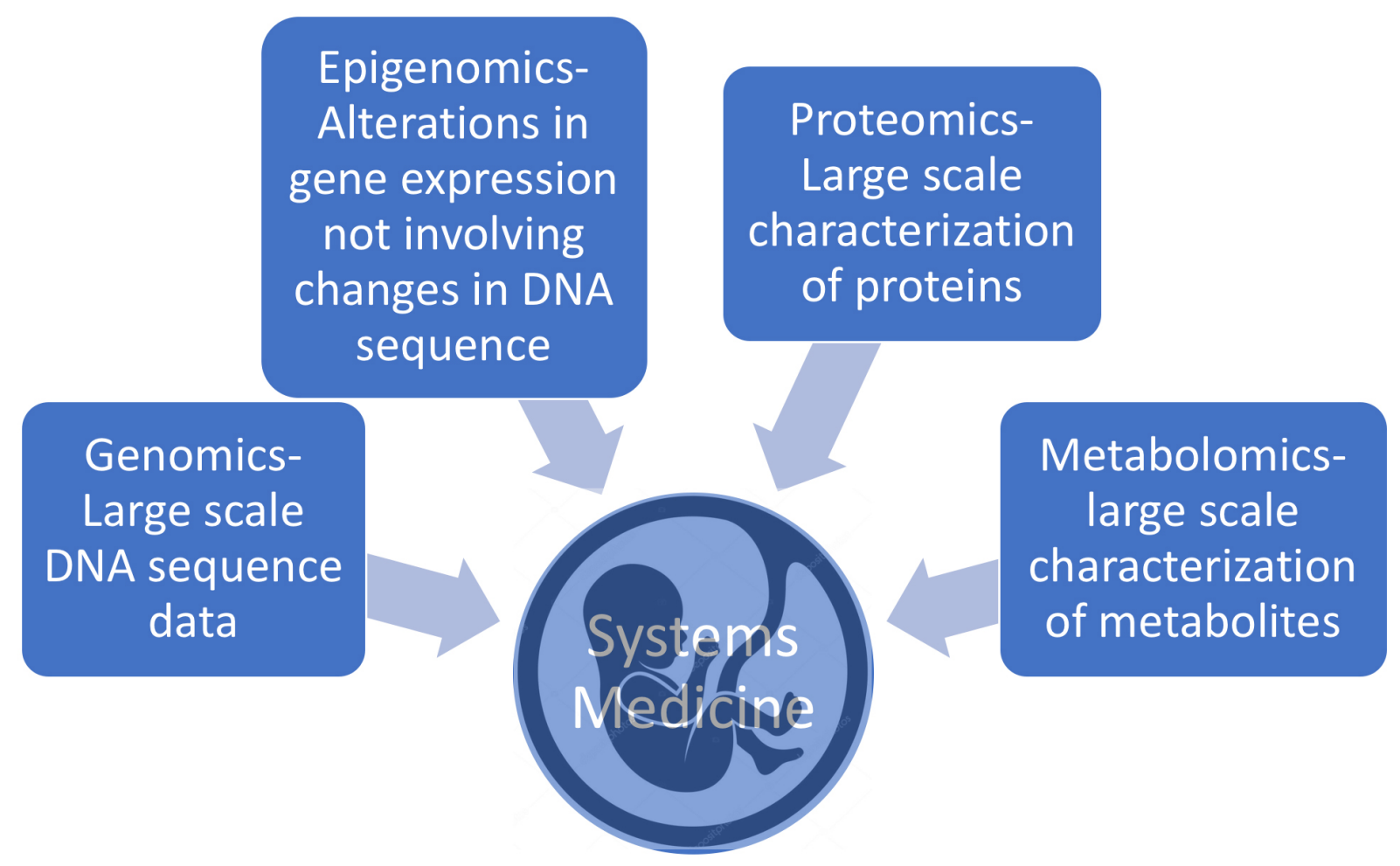

Fig. 1. Systems medicine integrates traditional medical practice with information gained from "omic" technologies, e.g., genomics, epigenomics, proteomics, and metabolomics.

\section{What is systems medicine?}

Systems medicine (see Fig. 1) integrates traditional medical practice and modern imaging techniques with information gained from "omic" technologies [13-15]. The primary goal is to improve and individualize patient care. Omics technologies provide comprehensive information on the genetic composition (genomics), the epigenetic alterations (epigenomics), the protein composition (proteomics), and the metabolite composition (metabolomics) of a biosample [16]. These technologies are becoming very cost-competitive and reveal an unprecedented degree of molecular detail useful in disease diagnosis, prognosis, and therapy. For example, the cost of whole-genome single nucleotide polymorphism (SNP) genotyping (more on this below) is about $\$ 200-\$ 500$ depending on the number of markers (1.4 to 4.5 million).

A hallmark of systems biology is the utilization of an integrative rather than a reductionist approach with an emphasis on cross-disciplinary collaborations [17]. Systems biology is ideal for studying and understanding complex biological systems such as neurodevelopment and neuropharmacology. Systems medicine begins by applying systems biology to clinical medicine. It can have added dimensions such as bioethical considerations, increased interdisciplinary collaboration, and the complex task of integrating multi-omic data sets into valuable information for making clinical decisions $[18,19]$. In contrast to system biology, systems medicine can also contribute to public health policies and the design of optimal health care delivery systems.

Bioinformatics provides the analytical tools required to integrate multi-omic data streams into practical clinical applications. Artificial intelligence (AI) bioinformatics will eventually empower healthcare providers with the tools needed to mine large omic data sets for clinical applications. The very large-scale nature of omics data sets will require specialized medical AI applications. These applications eventually will develop the ability to communicate evidence-based conclusions to healthcare providers and effectively integrate omic data into electronic medical records $[20,21]$.

\subsection{Why a systems medicine approach to cannabinoid issues in pediatrics?}

The application of systems medicine to pediatrics has been progressing for the last decade, but very few publications have focused on health issues related to cannabinoids [22-28]. The National Academies of Sciences has published an outstanding report on the general health effects of cannabis and cannabinoids [29]. This report covered general cannabis-related health issues (both therapeutic and adverse) from 1999 to 2016 but did not cover basic, nonhuman research results. In addition, a very limited number of publications have focused on issues related to cannabinoid use in the pediatric population [30,31]. 


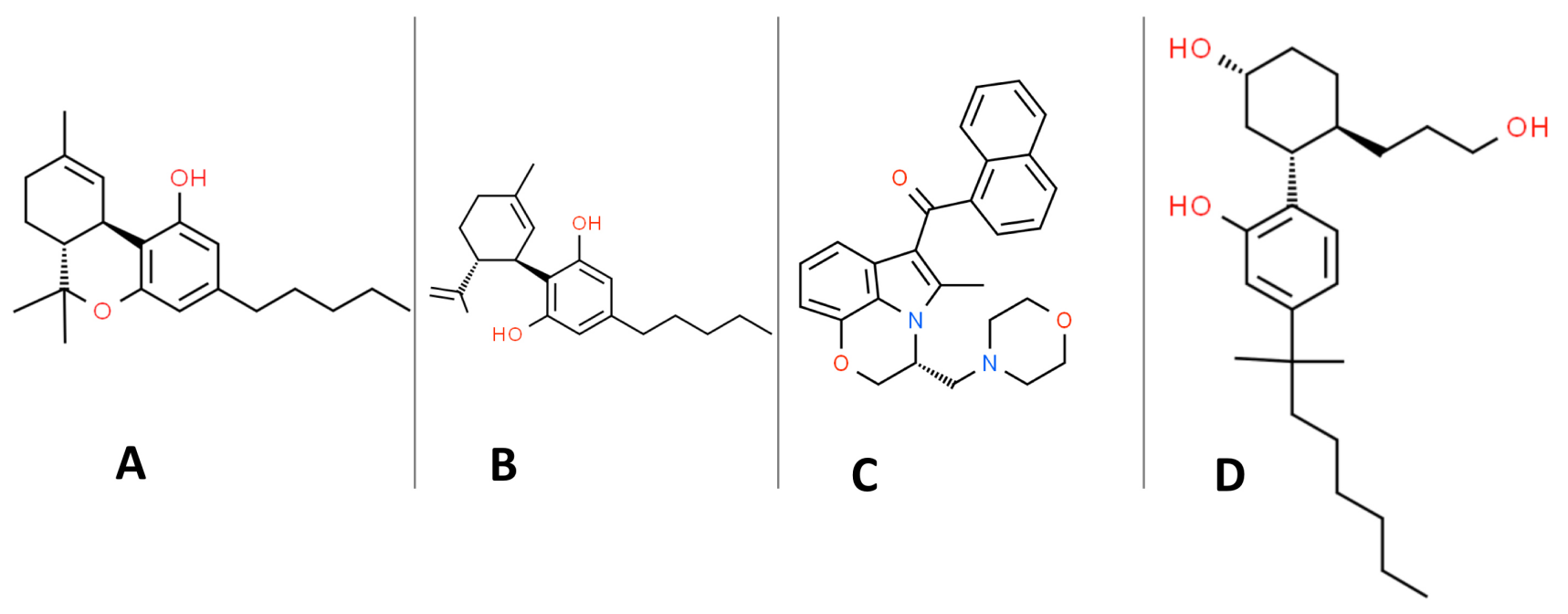

Fig. 2. Organic structures of: (A) delta-9-THC. (B) (-)-trans-cannabidiol (CBD). (C) WIN 55,212-2. (D) CP-55,940.

The review presented here will address the background of cannabinoid pharmacology only to the extent that it advances a systems medicine approach. Moreover, we will address relevant basic in vitro research and results from animal models. As detailed below, basic research into the genetic variants of key protein players in cannabinoid pharmacodynamics (e.g., the cannabinoid receptors) is essential for understanding the molecular mechanisms behind the possible short- and long-term adverse effects of cannabinoids and for predicting clinical variability in cannabinoid responses. Thus, our first step in this review is to address some basic definitions.

\section{What are cannabinoids?}

Surprisingly, the definition of "cannabinoids" in much of the scientific literature is neither precise nor uniform. The National Cancer Institute definition is somewhat narrow in defining cannabinoids as "a type of chemical in marijuana that causes drug-like effects all through the body, including the central nervous system and the immune system" [32]. While "cannabis" refers to the Cannabis sativa plant, "marijuana" is generally more specific in referring to the dried leaves and flowers of the Cannabis sativa plant. Cannabinoids like delta-9-tetrahydrocannabinol (delta-9THC) and cannabidiol (CBD) (see Fig. 2) are indeed found in marijuana, along with at least 100 other minor cannabinoids [33].

\subsection{Phytocannabinoids ( $p C B s$ )}

The cannabinoids found in the cannabis plant are collectively termed phytocannabinoids (pCBs), and there are at least 15 subclasses of cannabinoids. The pharmacology of pCBs is, therefore, intrinsically convoluted due to this complex mix of cannabinoids. Moreover, it has been suggested that the pharmacological effects of cannabis are due to an "entourage effect" wherein the complex mixture of pCBs play synergistic roles not readily understood by the effects of the isolated cannabinoid chemical species [34].

\subsubsection{Delta-9-THC content differentiates hemp from} marijuana

Both hemp and marijuana belong to the same species, i.e., Cannabis sativa, and have similar appearance and smell. Hemp, however, differs from marijuana in its cannabinoid composition: hemp primarily contains CBD with only low concentrations of delta-9-THC. Hemp is legally defined by the USA Hemp Farming Act of 2018 as "the cannabis plant having less than $0.3 \%$ delta- 9 -THC by dry weight". This act also removed hemp from Schedule I of the Controlled Substances Act, thereby essentially legalizing CBD under specific circumstances [35]. The term "cannabis" is traditionally thought to refer to a genus that includes two species, Cannabis sativa, and Cannabis indica, but recent thought suggests that "ubiquitous interbreeding and hybridization of Sativa and Indica has rendered their distinction almost meaningless" [36]. The taxonomy of cannabis remains controversial [34].

3.1.2 CBD products are generally thought to be legal and have some pediatric therapeutic use

Marijuana remains illegal under federal law despite many states having legalized medical marijuana and/or recreational marijuana [37]. CBD products are generally thought to be legal if made from hemp and not marketed as having any therapeutic use unless specifically approved by the Food and Drug Administration (FDA). Recently, the FDA has approved Epidiolex to treat Dravet syndrome and Lennox-Gastaut syndrome in patients two years of age and older. These syndromes are epileptic encephalopathies that manifest during early childhood and are typically very difficult to treat [38]. Epidiolex is a plant-based CBD solution 
that is taken as an oral medication. The mechanisms by which Epidiolex could exert an anti-epileptic effect have recently been reviewed [39]. The fact that CBD, in the form of Epidiolex, has an FDA-approved use prevents it from being sold as a dietary supplement [40]. Nevertheless, a cursory look at CBD oil marketing on the internet shows all the earmarks of a dietary supplement. Dietary CBD oil supplements are sold at the checkout counter of many supermarkets.

3.1.3 CBD has some promise for treating a variety of substance abuse disorders

CBD has some promise as a treatment for various substance abuse disorders, including opioid use disorder [41] and cannabis use disorder [42]. Opioid use disorder during pregnancy is the underlying cause of neonatal abstinence syndrome [15]. A recent phase 2, double-blind, placebocontrolled, randomized study in a 16 to 60 -year-old population, found CBD to be effective in treating cannabis use disorder with no serious short-term side effects [42]. Campbell et al. [30] noted that CBD is a powerful inhibitor of CYP450 enzymes and therefore interferes with drug metabolism. This suggests that pharmacists have an important role in issues related to CBD use (and cannabinoid use in general) [30].

\subsubsection{Medical marijuana and pregnancy}

Marijuana is the most widely used drug during pregnancy [43]. Medical marijuana or medical cannabis (the preferred name) refers "to using the whole, unprocessed marijuana plant or its basic extracts to treat symptoms of illness and other conditions" [9]. It should be noted that the FDA does not recognize medical cannabis as a medicine despite many states having legalized this substance. The three primary reasons cited for cannabis use during pregnancy are: (1) to decrease stress or anxiety; (2) to minimize nausea or vomiting (morning sickness); (3) pain relief [44]. Morning sickness occurs during the first trimester of pregnancy and is very common, occurring in about $50 \%$ of all pregnancies [45]. While much research is needed, the available evidence shows that cannabis use during pregnancy and postpartum is associated with long-term adverse neurodevelopmental outcomes [46]. Work by Barbosa-Leiker et al. [47] emphasizes the need to utilize a "harm reduction" approach to help reduce cannabis use both during pregnancy and postpartum. Smoking marijuana during pregnancy is also associated with lower birth weight which is similarly associated with cigarette smoking in the perinatal period [48]. Moreover, the robust oxidative stress caused by smoke (in general) could contribute to low weight birth outcomes in pregnant women who smoke cigarettes and/or marijuana [25].

\subsubsection{Marijuana use and breastfeeding}

Marijuana use during gestation and through breastfeeding will expose the fetus/child to lipophilic cannabi- noids since these compounds freely cross the placenta and concentrate in breastmilk [49]. A study by Perez-Reyes, et al. [50] found that the concentration of delta-9-THC in breastmilk was eight times higher than in maternal plasma and THC was still detectable in breastmilk up to six days after the last reported use. Therefore, it is recommended that breastfeeding mothers abstain from marijuana use [46,51]. Endocannabinoids (see below) from the mother are also found in breastmilk, with much higher levels of 2-AG than AEA [52].

\subsubsection{Edible phytocannabinoids}

With the legalization of medical and recreational marijuana in many states, it is not surprising that marketing efforts are increasingly aimed at promoting marijuana consumption. There has been rapid growth in various types of edible marijuana products. Traditionally, it has mostly been brownies, but there is now a wide variety of candies and other food items [53]. When delta-9-THC is ingested, it is more slowly absorbed into the bloodstream than from smoking, creating a lag before experiencing its psychoactive effects [54]. This ingestion can cause overconsumption of marijuana during the lag period. There can also be interactions with other medications when delta-9-THC is ingested due to the involvement of hepatic detoxification mechanisms. In contrast, inhaled delta-9-THC directly exerts its effects on the brain [55]. The edibles' packaging raises concerns about children eating these edibles, innocently thinking they are candies they are usually allowed to consume. This risk is heightened because the dosage of these edibles is typically much higher than what is considered a safe dose [53]. In a study by Wang et al. [56], after the legalization of marijuana in Colorado, there was an increase in emergency department visits by young children due to marijuana ingestion. Most of these cases involved the consumption of edibles. A study by Friese et al. [57] has shown considerable misinformation among adolescents who perceive edibles as less risky than inhaled marijuana, thereby promoting earlier first use. Washington and Colorado have added regulations to marijuana sales that prevent edibles from being packaged and advertised to children. Still, neither state requires packaging to look distinguishable from other food items [53].

\subsection{Synthetic cannabinoids ( $s C B s$ )}

In addition to $\mathrm{pCBs}$, we now have a wide variety of synthetic cannabinoids (sCBs) that are typically designer drugs not found naturally. These sCBs are generally members of a new group of drugs termed "new psychoactive substances" [58]. To complicate matters further, sCBs are often sprayed on herbs and spices, sometimes with noncannabinoid psychoactive drugs [29]. sCBs cannot be considered as safe alternatives to phytocannabinoids $[59,60]$. sCBs are a very commonly used illegal drug in teenagers and young adults [59]. 
Table 1. Cannabinoids and examples.

\begin{tabular}{lccc}
\hline Class & Abbreviation & \multicolumn{2}{c}{ Examples } \\
\hline Phytocannabinoids & $\mathrm{pCBs}$ & 9-tetrahydrocannabinol & cannabidiol \\
Synthetic cannabinoids & $\mathrm{sCBs}$ & $\mathrm{CP}$ & WIN \\
Endocannabinoids & $\mathrm{eCBs}$ & Anandamide & 2-arachidonoylglycerol \\
\hline
\end{tabular}

Both "K2" and "Spice" are examples of commercial preparations that contain sCBs. At least 21 different sCBs have been detected in commercial preparations [59]. There are various types of synthetic cannabinoids split into five or more classifications (classical, nonclassical, hybrid, aminoalkylindole, eicosanoid, and others) based on their chemical structure. The most studied sCBs are CP-55,940 (CP) and WIN-55,212-2 (WIN) (Fig. 2). There are many concerns and unanswered questions about the health-related side-effects, toxicity, and addictive potential of these sCBs [61]. WIN is an aminoalkylindole derivative producing effects like delta-9-THC, even though it has an entirely different chemical structure. As detailed further below, WIN is a full agonist for CB1R and CB2R, whereas delta9-THC is a weak partial receptor agonist for both CB1R and CB2R [62]. WIN also has about 19-fold higher specificity for CB2R compared to CB1R [63]. After administration is discontinued, WIN is eliminated faster from circulation than delta-9-THC, suggesting that WIN may induce a more robust withdrawal response than delta-9-THC [59]. CP (Fig. 2D) is a nonclassical, bicyclic lipophilic cyclohexylphenol sCB and is a full agonist for CB1R and CB2R. $\mathrm{CP}$ is more potent than delta-9-THC and recent work in an animal model suggests this $\mathrm{SCB}$ may selectively disrupt lipids in young brains compared to adult brains [64].

\subsection{Endocannabinoids (eCBs) and the endocannabinoid system (ECS)}

In addition to $\mathrm{pCBs}$ and $\mathrm{sCBs}$, there are naturally occurring cannabinoids (endocannabinoids or eCBs) in all major subdivisions of bilaterians, i.e., animals with bilateral symmetry [65]. For example, both AEA and 2-AG are major eCBs (see Table 1), and their structures are provided in Fig. 3 [66]. eCBs were discovered in the search for the mammalian receptors responsible for binding pCBs [66]. As detailed more below, the signaling events that arise from the binding of eCBs to their cannabinoid protein receptors (see Fig. 4), along with the set of molecules capable of modulating these signaling events, are called the endocannabinoid system (ECS). Genetic variants in the ECS will be discussed below since they likely play a role in modulating the potential adverse and therapeutic effects of cannabinoids.

\section{Which cannabinoids are psychoactive?}

Delta-9-THC is universally classified as being the primary psychoactive agent present in marijuana. In colloquial parlance, the term "high" is often used to describe the psychoactive effects of delta-9-THC. "High" is not a particu-

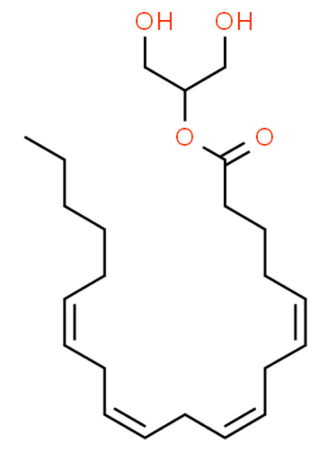

A

Fig. 3. Organic structures of: (A) 2-arachidonoylglycerol. (B) anandamide.

larly useful term since individual responses to delta-9-THC can vary from depression to well-being, and even transient psychotic symptoms [67-69]. In contrast to most humans or squirrel monkeys, rodents are averse to delta-9-THC and will not self-administer this CB [70]. The effects of delta-9THC can be highly variable and dependent upon the age of the individual, the dose and form of delta-9-THC, the presence or absence of other cannabinoids, and genetic factors. From a pediatric perspective, it is vital to distinguish the short-term acute effects of cannabinoids from the chronic effects that could be irreversible.

In contrast to delta-9-THC, CBD is often described as being non-psychoactive or non-psychotropic, c.f. [30]. A psychoactive substance is defined by the WHO as a substance that "when taken in or administered into one's system, affects mental processes, e.g., cognition" [71]. The National Institute on Drug Abuse Blog Team defines psychoactive drugs as those that "act on the central nervous system and alter its normal, everyday activity, causing changes in mood, awareness, and behavior" [72]. This webpage lists caffeine as a licit psychoactive drug. CBD is widely used by consumers hoping that it will positively affect anxiety, pain, or insomnia, i.e., mental processes. While CBD certainly lacks the psychoactive effects of delta-9-THC, current evidence supports its potential use for treating a variety of anxiety disorders, but further clinical trials will be needed [73]. Hammell et al. [74] found that transdermal CBD reduced inflammation and pain-related behaviors in a rat model of arthritis. While this research supports the role of CBD in pain management, it is only relevant to CBD in the form of a topical gel, not the typical rubbing of CBD oil near an arthritic joint or by an oral CBD capsule. 


\section{The cannabinoid receptors help define cannabinoids and their functions}

Genetic variants and the epigenetic regulation of proteins in the ECS are prime candidates for modulating the effects of cannabinoids. Moreover, cannabinoids can be more precisely defined by their interactions with and effects on the ECS. Therefore, the molecular perturbations of the ECS caused by $\mathrm{pCBs}$ and $\mathrm{sCBs}$ play a central role in understanding their potential pediatric consequences. Both the classic cannabinoid receptor type 1 (CB1R) and type 2 (CB2R) are vital components of the ECS, and both are class A G-protein coupled receptors (GPCRs) [75]. The organ, tissue, cellular and subcellular distribution of cannabinoid receptors are pivotal in understanding the effects of cannabinoids. Moreover, characterizing the dynamic spatial distribution of biomolecules is a component of system medicine [12]. CB1Rs are highly expressed in the central nervous system (CNS) but also present in peripheral organs (e.g., the gastrointestinal tract and the urinary tract) as well as immune cells [76]. While CB2 receptors are expressed more highly than $\mathrm{CB} 1$ receptors on immune cells both these receptors play significant roles in modulating many aspects of the immune system [77,78]. As reviewed by Turcotte et al. [79], CB2Rs are absent from most non-immune tissues except for the pancreas, lung, and uterus where the levels are relatively low. Strong evidence also suggests that CB2Rs are also expressed in specific areas of the brain with the potential to regulate drug addiction [80]. This review will emphasize the role of the ECS in the CNS, but cannabinoid pharmaceuticals may play a role in modulating immune disorders significant in pediatrics (e.g., childhood autoimmune disorders).

\subsection{Retrograde cannabinoid signaling, behavior, and neuronal plasticity}

We will briefly review the role of retrograde eCB signaling in the ECS with the limited goal of identifying key ECS protein/gene players (see Fig. 4). Genetic variants in these proteins could be relevant to cannabinoid use disorder (CUD) and their responses to cannabinoids. Excellent and more extensive reviews of the $\mathrm{eCB}$ signaling are available $[66,76,81,82]$. eCB receptors on neurons in the peripheral and CNS inhibit neurotransmitter release by "retrograde" eCB signaling [81]. CB1R (and CB2R) bind both AEA and 2-AG, naturally occurring "retrograde neurotransmitters." However, AEA binding to CB1R is much more robust than binding to CB2R [82]. Typically, neurotransmitters are released from the presynaptic neuron, cross the neuronal synapse and bind to receptors on the postsynaptic neuron and elicit responses. In contrast, retrograde neurotransmitters, such as eCBs and nitric oxide, are synthesized and released by the postsynaptic neuron and diffuse back (retro) across the synaptic cleft, where they bind and activate receptors on presynaptic neurons $[83,84]$.
As outlined in Fig. 4, depolarization of the postsynaptic neuron opens a voltage-gated $\mathrm{Ca}^{2+}$-channel (VGCC) promoting the $\mathrm{Ca}^{2+}$-stimulated biosynthesis of eCBs. More specifically, the multistep-amidation of arachidonic acid (20:4n6) with ethanolamine forms AEA ( $N$-arachidonoylethanolamide), and the multistep-esterification of $20: 4 \mathrm{n} 6$ forms 2-AG (2arachidonoylglycerol) [82]. eCBs released from the postsynaptic neuron travel (retro) to $\mathrm{CB} 1 \mathrm{R}$ (or CB2R) on the presynaptic neuron resulting in the exchange of a GTP for GDP and the subsequent dissociation of the G $\alpha$-GTP complex from the GPCR. The presynaptic G $\alpha$-GTP complex then inhibits $\mathrm{Ca}^{2+}$ influx through the VGCC and activates an inwardly rectifying $\mathrm{K}^{+}$-channel, resulting in an inhibition of presynaptic neurotransmitter release, which would otherwise bind to neurotransmitter receptors on the postsynaptic neuron [85]. Thus, this retrograde signaling process can inhibit the release of either excitatory or inhibitory neurotransmitters.

The enzymes that synthesize or hydrolyze eCBs are also critical components of the ECS [86]. Enzymatic hydrolysis of eCBs results in their inactivation and cessation of subsequent signaling events. Monoglyceride lipase (MGL) deactivates 2-AG by promoting its hydrolysis to glycerol and 20:4n6 [87]. Similarly, fatty acid amide hydrolase (FAAH), in the postsynaptic terminal, catalyzes the hydrolysis and inactivation of AEA ( Narachidonoylethanolamide or anandamide) to ethanolamine and $20: 4 n 6$ [88].

2-AG is considered a "full agonist" for both CB1R and CB2R with a low to moderate binding affinity and elicits a robust physiological response [82]. In contrast, AEA is a high affinity "partial agonist" for CB1R but largely inactive at $\mathrm{CB} 2 \mathrm{R}$, i.e., it has a lower binding affinity and elicits a less robust response [82]. Delta-9-THC is a partial agonist for both CB1R and CB2R and can produce the same inhibition of presynaptic neurotransmitter release as eCBs (see Fig. 4) [89]. Moreover, it is via this effect on retrograde signaling that delta-9-THC is thought to modulate its many CNS effects. In contrast to delta-9-THC, CBD has a much lower affinity to CB1R and CB2R [90]. Moreover, CBD acts as an indirect antagonist of cannabinoid agonists [89]. As noted by Tai et al. [59], many of the sCBs that mimic the effects of delta-9-THC are full agonists of CB1, and their pharmacology and toxicology are not well-understood.

Cannabinoids, via their retrograde signaling, are known to affect synaptic plasticity, i.e., the continual alterations in neuronal connections and their dynamic information processing $[66,91]$. In a comprehensive review, Schaefer et al. [92] define synaptic plasticity as "the potential of neural activity patterns generated by experiences to induce alterations in synaptic connectivity". Among the behaviors modulated by cannabinoids are learning, memory, habituation, reward, addiction, pain perception, and anxiety [66]. Neuroplasticity can be further defined as either short- 


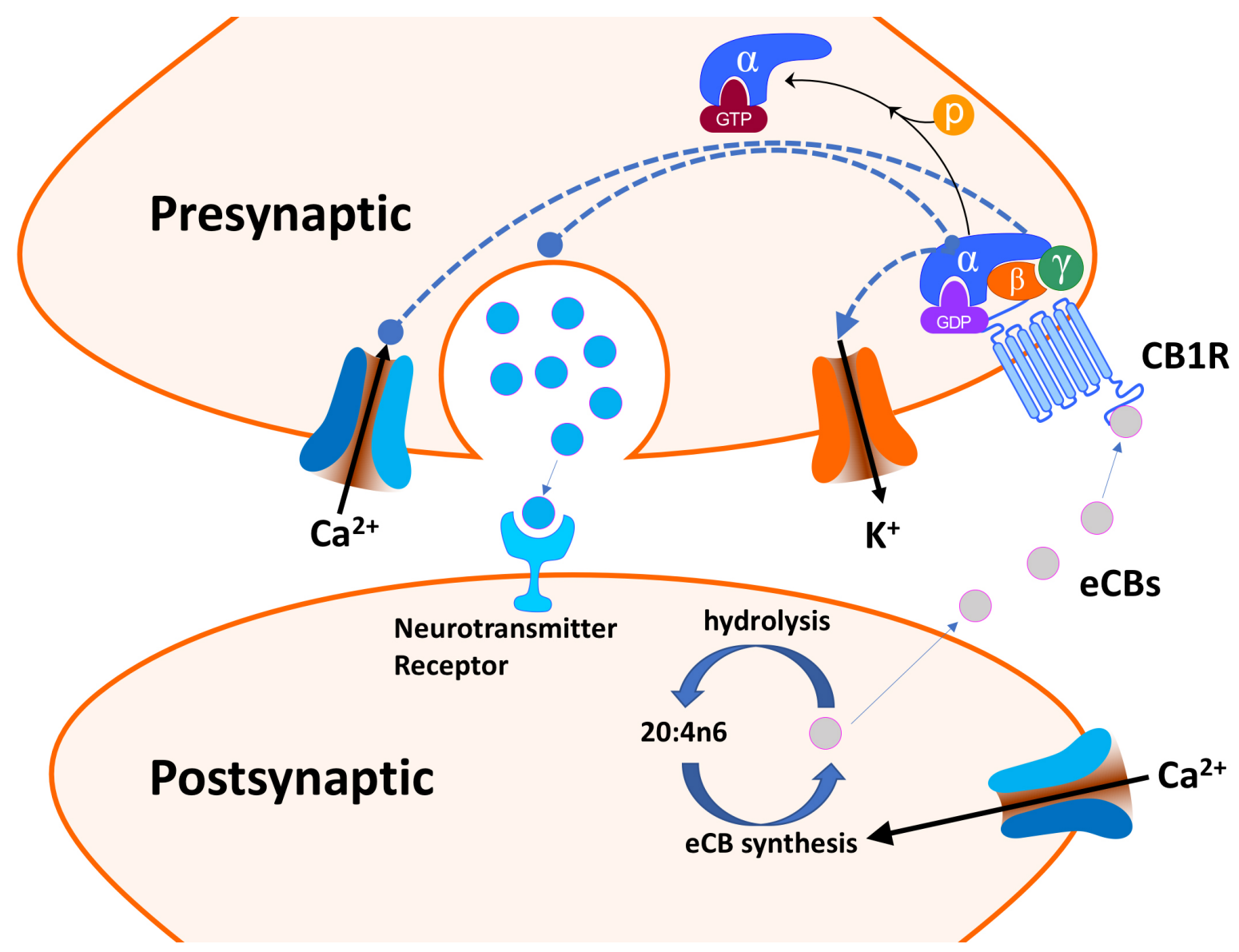

Fig. 4. Endocannabinoid (eCB) retrograde signaling (simplified). Depolarization of the postsynaptic neuron opens a voltage-gated $\mathrm{Ca}^{2+}$-channel (VGCC) promoting the $\mathrm{Ca}^{2+}$ stimulated synthesis of eCBs derived (in part) from arachidonic acid (20:4n6). Enzymatic hydrolysis of eCBs results in their inactivation. eCBs released from the postsynaptic neuron travel (retro) to the CB1 receptor (CB1R) on the presynaptic neuron resulting in the exchange of a GTP for GDP and the dissociation of the G $\alpha$-GTP complex from the G proteincoupled receptor (GPCR). The presynaptic G $\alpha$-GTP complex then inhibits $\mathrm{Ca}^{2+}$ influx through the VGCC (dotted line with sphere end) and activates (dotted line with arrow end) the $\mathrm{K}^{+}$-channel. These alterations in ion fluxes inhibit the release of presynaptic neurotransmitters (light blue spheres), which would otherwise bind to neurotransmitter receptors on the postsynaptic neuron.

term (sub-second time scale) or long-term (minutes, hours, days, years). Of particular pediatric concern are the critical periods in neurodevelopment during which alterations in long-term synaptic plasticity are occurring rapidly and result in the formation of permanent and irreversible neural networks [92]. Thus, the interplay between cannabinoids and the genetic and epigenetic modulators of longterm synaptic plasticity is central to a systems medicine approach.

\subsection{How does delta-9-THC exert its effects on the brain}

The brain's ventral tegmental area (VTA) region plays a key role in reward behavior with the amount of dopamine released into the VTA being highly correlated with reward effects [93]. Research in an animal model suggests that the behavioral effects of delta-9-THC are strongly influenced by its binding to $\mathrm{CB} 1$ receptors on both glutamate-releasing (glutamatergic) neurons and gamma-aminobutyric acidreleasing (GABAergic) neurons in the VTA. The binding of delta-9-THC to these CB1 receptors inhibits the activity of both these neuronal types [69]. Glutamatergic neurons produce a reward effect by promoting dopamine release from dopaminergic neurons. In contrast, GABAergic neurons in the VTA produce an aversion response by inhibiting dopamine release from dopaminergic neurons [94]. Consequently, delta-9-THC binding to CB1 receptors on glutamatergic neurons results in an aversion response, whereas delta-9-THC binding to GABAergic neurons results in a reward response. Therefore, the relative expression of CB1 receptors on glutamatergic- and GABAergicneurons is thought to be an essential factor influencing how individuals (or species) respond to delta-9-THC [69].

\section{Role of the endocannabinoid system in neurodevelopment}

The ECS plays important roles in the development of the CNS, such as the differentiation of neural progenitor 
cells (NPCs) and the commitment, survival, and synaptic plasticity of NPCs [86]. NPCs are multipotent stem cells that give rise to almost all the cell types of the CNS [95]. The ECS has also been shown to contribute to neuronal migration [86]. CB1Rs are implicated in axonal elongation, synaptogenesis, and myelinogenesis [96]. Disruptions to the temporally ordered sequence of ECS signaling by pCBs or sCBs may lead to disturbances in the normal functions of eCBs [86]. In animal models, changes to male copulatory behavior [97], learning ability [98], stress response [99], and pain sensitivity [100] in adult mice are linked to perinatal marijuana exposure.

The ECS plays a vital role in neurodevelopment during adolescence, including pruning and synaptic plasticity [101]. The use of pCBs and sCBs has been connected to ECS signaling abnormalities affecting both reward and cognition pathways [102]. Increased stress responsivity, negative emotional states, and drug cravings can all be linked to altered eCB signaling [103]. Epidemiologic studies have linked cannabis use in adolescence to an increased risk of neuropsychiatric disorders, including cognitive deficits, psychotic symptoms, and drug abuse [104,105]. There is also an increased risk for cocaine and polysubstance abuse when cannabis use is initiated during adolescence [106]. There may be other environmental and developmental factors at work in these responses [105].

\section{Cannabinoid effects on newborns}

There are many difficulties in obtaining a clear picture of the real effects of perinatal marijuana on infants, mainly because there are no human randomized control studies (for ethical considerations). Delta-9-THC can readily cross the placenta, and thus enter the fetal bloodstream [107]. Some of the confounding factors come from polysubstance use (i.e., alcohol, cigarettes, opioids, etc.) with the amount and frequency primarily being self-reported [46]. There are also socio-economic considerations such as malnutrition, education level, poverty, and lack of folic acid supplementation that could increase risk [108]. Implantation of the fetus can be disturbed by delt-9-THC stimulating CB1R and disrupting trophoblast formation [109]. Other problems during pregnancy can follow such as miscarriage, growth restriction, pre-eclampsia, and preterm labor [110]. Hurd et al. [111] found that aborted fetuses exposed to marijuana showed decreased birth weight and fetal foot length negatively correlated with the amount of marijuana consumed. An additional study by Fried et al. [112] demonstrated that infants exposed to perinatal marijuana had significantly smaller head circumferences at birth. Future intelligence quotient is significantly linked to head growth during the first month of life [113]. A study from Canada assessing live births from 2007 to 2012 showed that cannabis use during pregnancy is associated with an increased risk of neurodevelopmental disorders by ten years of age, including autism spectrum disorder and attention deficit hyperactiv- ity disorder [107]. Further, the incidence of autism spectrum disorder was 4.00 per 1000 person-years in children exposed to cannabis, compared to 2.42 in children who were not exposed [107].

\section{The systems biology of hemp and marijuana}

A systems medicine approach to clinical conditions usually begins with the omics of individual patients or mother/fetus dyads. In most substance use disorder cases, the "substance" (e.g., opioids) is usually a drug with well-defined organic compositions and pharmacodynamics. Since hemp and marijuana are "herbal" entities with complex and variable cannabinoid compositions the cannabis "substance" at hand requires a more thoughtful characterization: systems biology ideally suited for this task. Despite its central importance, the systems biology of hemp is just beginning to be systematically well defined. Moreover, a complete review of this topic is beyond the scope of this paper. As detailed by Aliferis et al. [114], characterizing metabolomics of cannabis (termed cannabinomics) is an essential first step in understanding its adverse and potentially useful effects. However, the metabolomics of marijuana is further complicated by the combustion or high-temperature heating/vaporizing that often accompanies delivery which would certainly alter the metabolomics. A relevant example is delta-9-tetrahydrocannabinolic A acid (delta-9-THCA-A), a non-psychoactive precursor of delta-9-THC, which comprises about $90 \%$ of the "total" delta-9-THC in marijuana [115]. Heating converts most of the delta-9-THCA-A into delta-9-THC. Combustion is also likely to cause extensive oxidative alterations to many small organic molecules.

Since the legal definition of hemp versus marijuana rests on the content of delta-9-THC, it is reasonable to ask whether these plants only differ in the genes underlying delta-9-THC biosynthesis. Sawler et al. [116] addressed this question by a genome-wide single nucleotide (SNP) study of hemp $(\mathrm{N}=43)$ and marijuana $(\mathrm{N}=81)$ samples. These investigators found that the genetic differences between hemp and marijuana are not limited to the delta-9THC biosynthetic genes.

\section{The genomics of cannabis use and cannabis use disorder (CUD)}

Most users of cannabis do not develop CUD [117, 118]. Nevertheless, cannabis use or CUD during pregnancy is highly relevant in pediatrics and associated with significant problematic neonatal outcomes including preterm birth, low birth weight, hospitalizations, and death [119]. A key sign of CUD is the presence of withdrawal symptoms when abstaining from cannabis use [120]. A detailed and comprehensive review of CUD has recently been published [121]. Genomic studies (or omic studies in general) of cannabis use/CUD utilizing mother-infant dyads 
Table 2. Genes and SNPs associated with cannabis use disorder.

\begin{tabular}{lccc}
\hline Gene & Protein name/function & SNPs & Online detail \\
\hline CADM2 & CADM2/cell adhesion molecule 2 & rs2875907 & www.snpedia.com/index.php/Rs2875907 \\
CNR1 & CB1R/cannabinoid receptor 1 & rs806380 & www.snpedia.com/index.php/Rs806380 \\
& & rs2023239 & www.snpedia.com/index.php/Rs2023239 \\
CNR2 & CB2/cannabinoid receptor 2 & rs35761398 & www.snpedia.com/index.php/Rs35761398 \\
& & rs12744386 & www.snpedia.com/index.php/Rs12744386 \\
FAAH & FAAH/fatty acid amide hydrolase & rs324420 & www.snpedia.com/index.php/Rs324420 \\
MGL & MGL/monoglyceride lipase & rs604300 & www.ncbi.nlm.nih.gov/snp/rs604300 \\
Near CHRNA2 & nAChR $\alpha 2 /$ cholinergic receptor nicotinic alpha-2 subunit & rs56372821 & www.ncbi.nlm.nih.gov/gene/1135 \\
FOXP2 & FOXP2/forkhead box protein P2 & rs7783012 & www.ncbi.nlm.nih.gov/gene/93986 \\
\hline
\end{tabular}

have not yet been reported but this would be the optimal study design. However, we have some limited information on the genetic predispositions for cannabis use or CUD in adults which will be reviewed below. This genomic information could be potentially helpful in counseling pregnant or lactating women about their susceptibility to cannabis use/CUD. Counseling men about cannabis use in the preconception period may also prove useful (see below).

An extensive genome-wide association study (GWAS) found eight SNPs associated with lifetime cannabis use [122]. Collectively, these eight SNPs account for about $10 \%$ of the variance in lifetime cannabis use. The strongest association was found for SNPs (e.g., rs2875907) in the CADM2 gene, which codes for the cell adhesion molecule 2 (see Table 2). CADM2 is vital in synaptic cell adhesion and genetic variants of CADM2 have been associated with a variety of behavioral (e.g., risk-taking) and metabolic traits [123].

Classical genetic studies with twins have firmly established that CUD has a substantial heritability, with between $30-80 \%$ of the total variance in CUD risk explained by genetic factors [124,125]. Candidate gene-CUDs association studies have been reviewed by Agrawal et al. [125] and will only briefly be summarized. Genome linkage analysis points to the potential importance of CNR1, CNR2, FAAH, and MGL genes (see Table 2). As detailed above, both MGL and FAAH inactivate endocannabinoids by hydrolysis. However, genetic linkage studies have many limitations, and GWASs are considered superior at identifying genes associated with a phenotype [125].

A candidate gene-SNP association study by Hopfer $e t$ al. [126] found that the G; G genotype of SNP rs806380 in the CNR1 gene was associated with a lower odds of CUD in adolescents (see Table 2). The C allele of CNR1 SNP rs2023239 has also been associated with more significant withdrawal symptoms and a higher craving for cannabis [127]. Further work indicates that the $G$ allele of CNR1 SNP rs2023239 may enhance the neural response to cannabis in the reward area of the brain [128]. Candidate gene-SNP association studies have also implicated SNPs in the FAAH gene and the MGL gene as playing significant roles in CUD (see Table 2) [127-129]. Recent work also suggests that polymorphisms in CNR2 (see Table 2) are risk factors for schizophrenia in adult CUD subjects [130].

Large-scale GWAS studies found SNP rs56372821 near the CHRNA2 gene is highly associated with CUD in Danish and Icelandic populations [131,132]. The CHRNA2 gene encodes for the alpha-subunit of nicotinic acetylcholine receptors (nAChRs), which are components of ligand-gated ion channels widely expressed in the CNS. The biological mechanism (s) whereby CHRNA2 is functionally connected to CUD is not yet clear. These studies also identified rs7783012 in the FOXP2 gene as being a variant associated with CUD. The FOXP2 gene encodes a member of the forkhead/winged-helix (FOX) family of transcription factors which are important in language development and synaptic plasticity [132].

Commercial services are driving down the cost of extensive SNP genotyping (\$100-\$200/sample) and hold the potential for making significant contributions to improving healthcare delivery systems. Many of the SNPs associated with CUD are reported by these commercial services such as 23andme. Nevertheless, major obstacles remain for integrating genomics/omics data with electron health records $[133,134]$. Overcoming these obstacles will undoubtedly accelerate the application of systems medicine to both research and patient care.

\section{The epigenomics of cannabis use/CUD}

The clinical epigenetics of cannabis use has not been well studied in populations relevant to pediatrics. Still, such studies are critical for defining potential underlying molecular mechanisms pertinent to CUD and cannabinoid pharmacology [135]. Epigenomics refers to alterations in gene expression not caused by changes in DNA sequence, e.g., DNA methylation and histone modifications. In a prescient article, Smith et al. [136] reviewed the evidence connecting cannabis exposure during critical periods of brain development to epigenetic alterations relevant to neuropsychiatric diseases such as autism spectrum disorder (ASD) and attention deficit hyperactivity disorder (ADHD). Recent data shows that children exposed to cannabis in utero have an 
increased risk of ASD. The underlying mechanism for this association is unknown but cannabis-induced epigenetic alterations are a strong possibility. It is generally assumed that maternal rather than paternal cannabis use is a primary cause of any altered neurodevelopmental outcomes. This assumption may need reevaluation in light of a recent genome-wide epigenomic study linking paternal offspring ASD susceptibility to specific sperm DNA methylation patterns [137]. In a rat model, Slotkin et al. [138,139] has recently shown that paternal delta-9-THC administration or cannabis exposure can have adverse effects on neurodevelopment in the offspring. Future research is critically needed to determine the potential adverse effects of human paternal delta-9-THC use in the preconception time interval.

\section{The proteomics of cannabis use/CUD}

There is very minimal clinical proteomic information on cannabinoid use/CUD in adult populations and information on pediatric populations is even more lacking. We will briefly review the adult clinical proteomic information since this will provide potential focus areas for future pediatrics studies. In a small population, Jayanthi et al. [140] found that heavy adult marijuana users showed significant increases in serum levels of apolipoprotein C-III (apoC-III), which is a risk factor for cardiovascular disease. The mechanism for this apparent delta-9THC induced upregulation of apoC-III is not yet known. A recent study looked at proteomic and metabolomic alterations in plasma from a small adult population (24 total participants) of cannabis users and nonusers [141]. Plasma levels of delta-9-tetrahydrocannabinol carboxylic acid (delta-9-THC-COOH) correlate with 13 proteins relevant to pathways important in immune system regulation, i.e., interleukin-6 production, $\mathrm{T}$ lymphocyte regulation, apoptosis, kinase signaling pathways, and nuclear factor kappa-light-chain-enhancer of activated B cells. Future proteomic studies looking at relevant pediatrics populations are undoubtedly a high priority.

As detailed more below, urine is an excellent body fluid for pediatric omic analyses. Nedumaran et al. [142] examined urine protein biomarkers in a small population of adult cannabis users and nonusers. Proteomic analyses detected 1337 proteins in both groups: 19 proteins had a significantly different expression level in cannabis users. Moreover, 91 proteins were expressed only in the cannabis group and 46 proteins were only absent in this group. The application of pathway analysis suggested that the cannabis user group had alterations in innate immune responses and carbohydrate metabolism. These data are very encouraging since they support using urine as a biofluid for future omic analyses.

\section{The metabolomics of cannabis use/CUD}

Not surprisingly, the application of metabolomics to cannabinoids has primarily focused on characterizing the small bioactive molecules present in commercial cannabis products. This information is essential for documenting a user's exposure to the complex mixture of chemicals in cannabis: such basic information has been lacking in most clinical cannabis studies [114,143]. Equally important, however, is documenting the cannabinoids and cannabinoid metabolites in a biofluid/tissue sample after exposure to a cannabis product [144].

We have previously reviewed the application of metabolomics to issues surrounding neonatal abstinence syndrome. Much of that discussion is relevant to pediatric cannabinoid exposure: particularly, our discussion on the suitability of various body fluids/tissues for pediatric omic analyses [15]. Plasma, cord blood, and urine samples would all be excellent samples. Like opioids, delta-9-THC is very lipophilic. The endoplasmic reticulum hydroxylation of delta-9-THC yields the psychoactive 11-hydroxydelta-9-tetrahydrocannabinol (11-OH-THC), and oxidation of 11-OH-THC produces the inactive 11-nor-9-carboxyldelta-9-tetrahydrocannabinol (THC-COOH), which is excreted in urine as the glucuronic conjugate [144]. Thus, biofluid levels of delta-9-THC, 11-OH-THC, and THC$\mathrm{COOH}$ are essential metabolites that should be quantified in clinical cannabinoid studies. Given that many cannabis users also smoke cigarettes and may unknowingly be exposed to synthetic cannabinoids, clinical metabolomic analyses should ideally identify and quantify as broad a range of relevant small organic molecules as technically possible. Since cannabinoid exposure is likely to alter normal metabolites, these should also be quantified. Fortunately, rapid technological advances in metabolomics have made it possible to cost-effectively characterize an enormous number of metabolites (about 4000) in urine or plasma/serum samples [145-147].

\subsection{The exposome, cannabinoids, and polysubstance use}

A key systems medicine measure of environmental exposures is the "exposome" which is defined as "the measure of all the exposures of an individual in a lifetime and how those exposures relate to health" [148]. In practice, attempts to measure the exposome rely on modern metabolomic technologies such as liquid chromatographytandem mass spectrometry (LC-MS/MS) and nuclear magnetic resonance spectroscopy (NMR). Attempts to correlate the exposome to any potential cannabinoid-induced pathologies (e.g., psychosis) or therapeutic benefits are very limited at present and complicated by polysubstance use $[149,150]$. Nevertheless, the rapid development of exposome academic centers (e.g., ehe.jhu.edu/research/the-e xposome-collaborative/resources-links.html) and the emergence of exosome commercial services (e.g., daltonbioana lytics.com/) will accelerate the future application of exposome metabolomics to pediatric cannabinoid/polysubstance use research. Longitudinal urine samples are readily available from newborns from cotton balls inserted into diapers. 


\section{Conclusions}

Our review strongly supports the official policy from the American College of Obstetrics and Gynecology which recommends abstaining from marijuana use while pregnant and breastfeeding due to the potential neurodevelopmental risks to the fetus/newborn [151]. Nevertheless, both CBD and marijuana are often used (self-initiated) by women to treat nausea and vomiting during pregnancy (NVP), i.e., morning sickness [152,153]. Most cases of NVP occur only during the first trimester and subside before 20 weeks of gestation. Although rare, prolonged severe nausea and vomiting (SNVP) can occur during pregnancy and is associated with psychiatric and cognitive problems in children [154]. At present, it is not known if using any cannabinoids could be justified for treating SNVP. The rapid pace of marijuana legalization is presenting pediatricians with new challenges, particularly for adolescents. The mental health and cognitive problems associated with adolescent cannabinoid/polysubstance use have been sufficiently well documented to support active office-oriented interventions and patient/family educational efforts [155]. Some adolescents, neonates, and fetuses are likely more susceptible to the detrimental effects of cannabinoid/polysubstance exposure than others. Systems medicine and omic data may help identify these individuals so preventative/preemptive measures can be taken.

\section{Abbreviations}

11-OH-THC,

11-hydroxy-delta-9tetrahydrocannabinol; ADHD, attention deficit hyperactivity disorder; AI, artificial intelligence; apoC-III, apolipoprotein C-III; ASD, autism spectrum disorder; CADM2, cell adhesion molecule 2; CB1R, cannabinoid type 1 receptor; $\mathrm{CB} 2 \mathrm{R}$, cannabinoid type 2 receptor; $\mathrm{CBD}$, cannabidiol; $\mathrm{CB}$, cannabinoid; $\mathrm{CNS}$, central nervous system; COVID-19, coronavirus 2019; CUD, cannabinoid use disorder; delta-9-THC-COOH, delta9-tetrahydrocannabinol carboxylic acid; delta-9-THC, delta-9-tetrahydrocannabinol; delta-9-THCA-A, delta-9tetrahydrocannabinolic A acid; eCBs, endocannabinoids; ECS, endocannabinoid system; FAAH, fatty acid amide hydrolase; FDA, Food and Drug Administration; FOX, forkhead/winged-helix; GABA, gamma-aminobutyric acid; GPCRs, G-protein coupled receptors; GWAS, genome-wide association study; LC-MS/MS, liquid chromatography-tandem mass spectrometry; MGL, monoglyceride lipase; nAChRs, nicotinic acetylcholine receptors; NMR, magnetic resonance spectroscopy; NPCs, neural progenitor cells; NVP, nausea and vomiting during pregnancy; pCBs, phytocannabinoids; sCBs, synthetic cannabinoids; SNP, single nucleotide polymorphism; SNVP, severe nausea and vomiting during pregnancy; VGCC, voltage-gated $\mathrm{Ca}^{2+}$-channel; VTA, ventral tegmental area; WIN, WIN-55,212-2.

\section{Author contributions}

WLS and CPO wrote the initial draft. CPO, DST, DSS, and WLS contributed equally to the final manuscript.

\section{Ethics approval and consent to participate}

Not applicable.

\section{Acknowledgment}

Thanks to all the peer reviewers for their opinions and suggestions.

\section{Funding}

This research was supported in part by the National Institutes of Health grant C06RR0306551 and the East Tennessee State University Robert W. Summers Pediatric Research Endowment.

\section{Conflict of interest}

The authors declare no conflict of interest. WLS is serving as one of the Editorial Board members of this journal. We declare that WLS had no involvement in the peer review of this article and has no access to information regarding its peer review. Full responsibility for the editorial process for this article was delegated to GP.

\section{References}

[1] Young-Wolff KC, Sarovar V, Tucker LY, Conway A, Alexeeff S, Weisner C, et al. Self-reported Daily, Weekly, and Monthly Cannabis Use Among Women Before and During Pregnancy. JAMA NEtwork Open. 2019; 2: e196471.

[2] Miech RA, Patrick ME, O'Malley PM, Johnston LD, Bachman JG. Trends in Reported Marijuana Vaping among us Adolescents, 2017-2019. Journal of the American Medical Association. 2020; 323: 475 .

[3] Gaiha SM, Cheng J, Halpern-Felsher B. Association Between Youth Smoking, Electronic Cigarette Use, and COVID-19. The Journal of Adolescent Health. 2020; 67: 519-523.

[4] Wing C, Bradford AC, Carroll AE, Hollingsworth A. Association of State Marijuana Legalization Policies for Medical and Recreational Use with Vaping-Associated Lung Disease. JAMA Network Open. 2020; 3: e202187.

[5] Kirschner M. Systems Medicine: Sketching the Landscape. Methods in Molecular Biology. 2016; 82: 3-15.

[6] $\mathrm{Wu} \mathrm{C}$, Jew CP, Lu H. Lasting impacts of prenatal cannabis exposure and the role of endogenous cannabinoids in the developing brain. Future Neurology. 2011; 6: 459-480.

[7] Johnson SB, Blum RW, Giedd JN. Adolescent Maturity and the Brain: the Promise and Pitfalls of Neuroscience Research in Adolescent Health Policy. Journal of Adolescent Health. 2009; 45: 216-221.

[8] Pujol J, Vendrell P, Junqué C, Martí-Vilalta JL, Capdevila A. When does human brain development end? Evidence of corpus callosum growth up to adulthood. Annals of Neurology. 1993; 34: 71-75.

[9] NIDA. What is the scope of marijuana use in the United States? 2021. Available at: www.drugabuse.gov/publications/researc h-reports/marijuana/what-scope-marijuana-use-in-united-state s (Accessed: 20 April 2021).

[10] Challenges and Barriers in Conducting Cannabis Research. 
2017. Available at: www.ncbi.nlm.nih.gov/books/NBK425757/ (Accessed: 21 December 2021).

[11] Busquets-Garcia A, Bains J, Marsicano G. CB. Neuropsychopharmacology. 2018; 43: 4-20.

[12] Berlin R, Gruen R, Best J. Systems Medicine-Complexity within, Simplicity without. Journal of Healthcare Informatics Research. 2017; 1: 119-137.

[13] Apweiler R, Beissbarth T, Berthold MR, Blüthgen N, Burmeister Y, Dammann O, et al. Whither systems medicine? Experimental \& Molecular Medicine. 2018; 50: e453-e453.

[14] Fernández-González R, Muñoz-Barrutia A, Barcellos-Hoff $\mathrm{MH}$, Ortiz-de-Solorzano C. Quantitative in vivo microscopy: the return from the 'omics'. Current Opinion in Biotechnology. 2006; 17: 501-510.

[15] Stone WL, Wood DL, Justice NA, Shah DS, Olsen ME, Bharti D. The systems medicine of neonatal abstinence syndrome. Frontiers in Bioscience. 2020; 25: 736-759.

[16] Horgan RP, Kenny LC. 'Omic' technologies: genomics, transcriptomics, proteomics and metabolomics. The Obstetrician \& Gynaecologist. 2011; 13: 189-195.

[17] Systems biology is based on the understanding that the whole is greater than the sum of the parts. 2021. Available at: isbscien ce.org/about/what-is-systemsbiology/ (Accessed: 21 December 2021).

[18] Wolkenhauer O, Auffray C, Jaster R, Steinhoff G, Dammann O. The road from systems biology to systems medicine. Pediatric Research. 2013; 73: 502-507.

[19] Pinu FR, Beale DJ, Paten AM, Kouremenos K, Swarup S, Schirra HJ, et al. Systems Biology and Multi-Omics Integration: Viewpoints from the Metabolomics Research Community. Metabolites. 2019; 9: 76.

[20] Hamet P, Tremblay J. Artificial intelligence in medicine. Metabolism. 2017; 69: S36-S40.

[21] Pouladi N, Achour L, Li H, Berghout J, Kenost C, GonzalezGaray ML, et al. Biomechanisms of Comorbidity: Reviewing Integrative Analyses of Multi-omics Datasets and Electronic Health Records. Yearbook of Medical Informatics. 2016; 25 : 194-206.

[22] Tegnér J, Abugessaisa I. Pediatric systems medicine: evaluating needs and opportunities using congenital heart block as a case study. Pediatric Research. 2013; 73: 508-513.

[23] Minoo P, Wolkenhauer O, Guttentag S. Systems biology and pediatric research. Pediatric Research. 2013; 73: 499-501.

[24] Young J, Stone WL. Pediatric proteomics: an introduction. Frontiers in Bioscience. 2012; S4: 1078-1087.

[25] Stone WL, Bailey B, Khraisha N. The pathophysiology of smoking during pregnancy a systems biology approach. Frontiers in Bioscience. 2014; 6: 318-328.

[26] Stone WL, Schetzina K, Stuart C. Childhood obesity a systems medicine approach. Frontiers in Bioscience. 2016; 21: 10611075.

[27] Stone WL, Shah D, Hollinger SM. Retinopathy of prematurity an oxidative stress neonatal disease. Frontiers in Bioscience. 2016; 21: 165-177.

[28] Stone WL, Klopfenstein KJ, Hajianpour MJ, Popescu MI, Cook CM, Krishnan K. Childhood cancers and systems medicine. Frontiers in Bioscience. 2017; 22: 1148-1161.

[29] National Academies of Sciences, Engineering, and Medicine; Health and Medicine Division; Board on Population Health and Public Health Practice; Committee on the Health Effects of Marijuana: An Evidence Review and Research Agenda. The Health Effects of Cannabis and Cannabinoids: The Current State of Evidence and Recommendations for Research. The National Academies Press. 2017.

[30] Campbell CT, Phillips MS, Manasco K. Cannabinoids in Pediatrics. The Journal of Pediatric Pharmacology and Therapeutics.
2017; 22: 176-185.

[31] Simonian JS, Varanasi S, Diaz-Fong JP, Richards GJ, Van Nguyen A, Hoffman JA. A critical narrative review of medical cannabis in pediatrics beyond epilepsy, part II: neurodevelopmental, movement, and pain disorders. Pediatric Medicine. 2020.

[32] NIH. Available at: www.cancer.gov/publications/dictionaries/c ancer-terms/def/cannabinoid (Accessed: 21 December 2021).

[33] Atakan Z. Cannabis, a complex plant: different compounds and different effects on individuals. Therapeutic Advances in Psychopharmacology. 2012; 2: 241-254.

[34] Russo EB. The Case for the Entourage Effect and Conventional Breeding of Clinical Cannabis: No "Strain," No Gain. Frontiers in Plant Science. 2019; 9: 1969.

[35] The Brookings Institution. The Farm Bill, hemp legalization and the status of CBD: An explainer. 2018. Available at: www.brookings.edu/blog/fixgov/2018/12/14/the-far m-bill-hemp-and-cbd-explainer/ (Accessed 7 December 2021).

[36] McPartland JM. Systematics at the Levels of Family, Genus, and Species. Cannabis and Cannabinoid Research. 2018; 3: 203212.

[37] Doheny K. Marijuana, Hemp, CBD Oil: What's Legal and Where. 2019. Available at: https://www.webmd.com/pain-man agement/news/20190108/marijuana-hemp-cbd-whats-legal-a nd-where (Accessed: 8 January 2019).

[38] Jacob E, Jacob S. Emerging Treatments for Dravet and Lennox-Gastaut Syndromes. 2021. Available at: https://www.uspharmacist.com/article/emerging-treatment s-for-dravet-and-lennoxgastaut-syndromes (Accessed: 18 January 2019).

[39] Silvestro S, Mammana S, Cavalli E, Bramanti P, Mazzon E. Use of Cannabidiol in the Treatment of Epilepsy: Efficacy and Security in Clinical Trials. Molecules. 2019; 24: 1459.

[40] World Health Organization. Alcohol, Drugs and Addictive Behaviours Unit. Available at: www.who.int/teams/mental-hea 1th-and-substance-use/alcohol-drugs-and-addictive-behaviour s/drugs-psychoactive/cannabis (Accessed: 21 December 2021).

[41] Chye Y, Christensen E, Solowij N, Yücel M. The Endocannabinoid System and Cannabidiol's Promise for the Treatment of Substance Use Disorder. Frontiers in Psychiatry. 2019; 10: 63.

[42] Freeman TP, Hindocha C, Baio G, Shaban NDC, Thomas EM, Astbury D, et al. Cannabidiol for the treatment of cannabis use disorder: a phase $2 \mathrm{a}$, double-blind, placebo-controlled, randomised, adaptive Bayesian trial. The Lancet Psychiatry. 2020; 7: 865-874.

[43] Metz TD, Stickrath EH. Marijuana use in pregnancy and lactation: a review of the evidence. American Journal of Obstetrics and Gynecology. 2015; 213: 761-778.

[44] Ko JY, Coy KC, Haight SC, Haegerich TM, Williams L, Cox $\mathrm{S}$, et al. Characteristics of Marijuana Use During Pregnancy Eight States, Pregnancy Risk Assessment Monitoring System. Morbidity and mortality weekly report. 2020; 69: 1058-1063.

[45] https://americanpregnancy.org/healthy-pregnancy/pregnan cy-health-wellness/morning-sickness-during-pregnancy/ (Accessed: 7 December 2021).

[46] Badowski S, Smith G. Cannabis use during pregnancy and postpartum. Canadian Family Physician Medecin de Famille Canadien. 2020; 66: 98-103.

[47] Barbosa-Leiker C, Burduli E, Smith CL, Brooks O, Orr M, Gartstein M. Daily Cannabis Use during Pregnancy and Postpartum in a State with Legalized Recreational Cannabis. Journal of Addiction Medicine. 2020; 14: 467-474.

[48] Crume TL, Juhl AL, Brooks-Russell A, Hall KE, Wymore E, Borgelt LM. Cannabis Use during the Perinatal Period in a State with Legalized Recreational and Medical Marijuana: the Association between Maternal Characteristics, Breastfeeding Pat- 
terns, and Neonatal Outcomes. The Journal of Pediatrics. 2018; 197: 90-96.

[49] Mourh J, Rowe H. Marijuana and Breastfeeding: Applicability of the Current Literature to Clinical Practice. Breastfeeding Medicine. 2017; 12: 582-596.

[50] Perez-Reyes M, Wall ME. Presence of delta9tetrahydrocannabinol in human milk. The New England Journal of Medicine. 1982; 307: 819-820.

[51] Bertrand KA, Hanan NJ, Honerkamp-Smith G, Best BM, Chambers CD. Marijuana Use by Breastfeeding Mothers and Cannabinoid Concentrations in Breast Milk. Pediatrics. 2018; 142: e20181076.

[52] Di Marzo V, Sepe N, De Petrocellis L, Berger A, Crozier G, Fride $\mathrm{E}$, et al. Trick or treat from food endocannabinoids? Nature. 1998; 396: 636-636.

[53] MacCoun RJ, Mello MM. Half-Baked - the Retail Promotion of Marijuana Edibles. New England Journal of Medicine. 2015; 372: 989-991.

[54] Huestis M. Human Cannabinoid Pharmacokinetics. Chemistry \& Biodiversity. 2007; 4: 1770-1804.

[55] Friese B, Slater MD, Annechino R, Battle RS. Teen Use of Marijuana Edibles: a Focus Group Study of an Emerging Issue. The Journal of Primary Prevention. 2016; 37: 303-309.

[56] Wang GS, Roosevelt G, Heard K. Pediatric Marijuana Exposures in a Medical Marijuana State. JAMA Pediatrics. 2013; 167: 630.

[57] Friese B, Slater MD, Battle RS. Use of Marijuana Edibles by Adolescents in California. The Journal of Primary Prevention. 2017; 38: 279-294.

[58] NIH. Synthetic Cannabinoids (K2/Spice). Available at: www.dr ugabuse.gov/drug-topics/synthetic-cannabinoids-k2spice (Accessed: 7 December 2021).

[59] Tai S, Fantegrossi WE. Synthetic Cannabinoids: Pharmacology, Behavioral Effects, and Abuse Potential. Current Addiction Reports. 2014; 1: 129-136.

[60] Tai S, Fantegrossi WE. Pharmacological and Toxicological Effects of Synthetic Cannabinoids and their Metabolites. Neuropharmacology of New Psychoactive Substances. 2016; 2011: 249-262.

[61] Synthetic cannabinoids in herbal products. United Nations Office on Drugs and Crime. 2011.

[62] Acheson SK, Moore NLT, Kuhn CM, Wilson WA, Swartzwelder HS. The synthetic cannabinoid WIN 55212-2 differentially modulates thigmotaxis but not spatial learning in adolescent and adult animals. Neuroscience Letters. 2011; 487: 411-414.

[63] Poso A, Huffman JW. Targeting the cannabinoid CB2 receptor: modelling and structural determinants of CB2 selective ligands. British Journal of Pharmacology. 2008; 153: 335-346.

[64] Leishman E, Murphy MN, Murphy MI, Mackie K, Bradshaw HB. Broad and Region-Specific Impacts of the Synthetic Cannabinoid CP 55,940 in Adolescent and Adult Female Mouse Brains. Frontiers in Molecular Neuroscience. 2018; 11: 436.

[65] Mcpartland JM, Agraval J, Gleeson D, Heasman K, Glass M. Cannabinoid receptors in invertebrates. Journal of Evolutionary Biology. 2006; 19: 366-373.

[66] Luchicchi A, Pistis M. Anandamide and 2arachidonoylglycerol: Pharmacological Properties, Functional Features, and Emerging Specificities of the Two Major Endocannabinoids. Molecular Neurobiology. 2012; 46: 374-392.

[67] Atakan Z, Bhattacharyya S, Allen P, Martín-Santos R, Crippa JA, Borgwardt SJ, et al. Cannabis affects people differently: inter-subject variation in the psychotogenic effects of $\Delta 9$ tetrahydrocannabinol: a functional magnetic resonance imaging study with healthy volunteers. Psychological Medicine. 2013; 43: $1255-1267$.

[68] Chang L, Chronicle EP. Functional Imaging Studies in Cannabis
Users. The Neuroscientist. 2007; 13: 422-432.

[69] Han X, He Y, Bi G, Zhang H, Song R, Liu Q, et al. CB1 Receptor Activation on VgluT2-Expressing Glutamatergic Neurons Underlies $\Delta$ 9-Tetrahydrocannabinol ( $\Delta$ 9-THC)-Induced Aversive Effects in Mice. Scientific Reports. 2017; 7: 12315.

[70] Justinova Z, Goldberg S, Heishman S, Tanda G. Selfadministration of cannabinoids by experimental animals and human marijuana smokers. Pharmacology Biochemistry and Behavior. 2005; 81: 285-299.

[71] World Health Organization. Drugs (psychoactive). Available at: who.int/health-topics/drugs-psychoactive\#tab=tab_1 (Accessed: 7 December 2021).

[72] NIDA. Word of the Day: Psychoactive Drugs. 2010. Available at: archives.drugabuse.gov/blog/post/word-day-psychoactive-d rugs (Accessed: 7 December).

[73] Blessing EM, Steenkamp MM, Manzanares J, Marmar CR. Cannabidiol as a Potential Treatment for Anxiety Disorders. Neurotherapeutics. 2015; 12: 825-836.

[74] Hammell DC, Zhang LP, Ma F, Abshire SM, McIlwrath SL, Stinchcomb AL, et al. Transdermal cannabidiol reduces inflammation and pain-related behaviours in a rat model of arthritis. European Journal of Pain. 2016; 20: 936-948.

[75] www.nature.com/scitable/topicpage/gpcr-14047471/ cessed: 21 December 2021)

[76] Howlett AC, Abood ME. CB1 and CB2 Receptor Pharmacology. Advances in Pharmacology. 2017; 80: 169-206.

[77] Kaplan BLF. The role of CB1 in immune modulation by cannabinoids. Pharmacology \& Therapeutics. 2013; 137: 365374.

[78] Oláh A, Szekanecz Z, Bíró T. Targeting Cannabinoid Signaling in the Immune System: "High"-ly Exciting Questions, Possibilities, and Challenges. Frontiers in Immunology. 2017; 8: 1487.

[79] Turcotte C, Blanchet MR, Laviolette M, Flamand N. The CB2 receptor and its role as a regulator of inflammation. Cellular and Molecular Life Sciences. 2016; 73: 4449-4470.

[80] Chen D, Gao M, Gao F, Su Q, Wu J. Brain cannabinoid receptor 2: expression, function and modulation. Acta Pharmacologica Sinica. 2017; 38: 312-316.

[81] Castillo P, Younts T, Chávez A, Hashimotodani Y. Endocannabinoid Signaling and Synaptic Function. Neuron. 2012; 76: 70-81.

[82] Zou S, Kumar U. Cannabinoid Receptors and the Endocannabinoid System: Signaling and Function in the Central Nervous System. International Journal of Molecular Sciences. 2018; 19: 833.

[83] Moore M. Endocannabinoid Performance Through Retrograde Signaling. 2018. Available at: www.labroots.com/trending/ca nnabis-sciences/8519/endocannabinoids-performance-retrogr ade-signaling (Accessed: 7 December 2021).

[84] Alger BE. Retrograde signaling in the regulation of synaptic transmission: focus on endocannabinoids. Progress in Neurobiology. 2002; 68: 247-286.

[85] Guo J, Ikeda SR. Endocannabinoids Modulate N-Type Calcium Channels and G-Protein-Coupled Inwardly Rectifying Potassium Channels via CB1 Cannabinoid Receptors Heterologously Expressed in Mammalian Neurons. Molecular Pharmacology. 2004; 65: 665-674.

[86] Basavarajappa B, Nixon R, Arancio O. Endocannabinoid System: Emerging Role from Neurodevelopment to Neurodegeneration. Mini-Reviews in Medicinal Chemistry. 2009; 9: 448-462.

[87] Dinh TP, Carpenter D, Leslie FM, Freund TF, Katona I, Sensi $\mathrm{SL}$, et al. Brain monoglyceride lipase participating in endocannabinoid inactivation. Proceedings of the National Academy of Sciences. 2002; 99: 10819-10824.

[88] Gunduz-Cinar O, Hill MN, McEwen BS, Holmes A. Amygdala FAAH and anandamide: mediating protection and recov- 
ery from stress. Trends in Pharmacological Sciences. 2013; 34 : 637-644.

[89] Pertwee RG. The diverse CB1 and CB2 receptor pharmacology of three plant cannabinoids: delta9-tetrahydrocannabinol, cannabidiol and delta9-tetrahydrocannabivarin. British Journal of Pharmacology. 2008; 153: 199-215.

[90] Thomas A, Baillie GL, Phillips AM, Razdan RK, Ross RA, Pertwee RG. Cannabidiol displays unexpectedly high potency as an antagonist of $\mathrm{CB} 1$ and $\mathrm{CB} 2$ receptor agonists in vitro. British Journal of Pharmacology. 2007; 150: 613-623.

[91] Iremonger KJ, Wamsteeker Cusulin JI, Bains JS. Changing the tune: plasticity and adaptation of retrograde signals. Trends in Neurosciences. 2013; 36: 471-479.

[92] Schaefer N, Rotermund C, Blumrich E, Lourenco MV, Joshi P, Hegemann RU, et al. The malleable brain: plasticity of neural circuits and behavior - a review from students to students. Journal of Neurochemistry. 2017; 142: 790-811.

[93] Lupica CR, Riegel AC, Hoffman AF. Marijuana and cannabinoid regulation of brain reward circuits. British Journal of Pharmacology. 2004; 143: 227-234.

[94] Morales M, Margolis EB. Ventral tegmental area: cellular heterogeneity, connectivity and behaviour. Nature Reviews Neuroscience. 2017; 18: 73-85.

[95] Martínez-Cerdeño V, Noctor SC. Neural Progenitor Cell Terminology. Frontiers in Neuroanatomy. 2018; 12: 104.

[96] Fernández-Ruiz J, Berrendero F, Hernández ML, Ramos JA. The endogenous cannabinoid system and brain development. Trends in Neurosciences. 2000; 23: 14-20.

[97] Dalterio SL. Perinatal or adult exposure to cannabinoids alters male reproductive functions in mice. Pharmacology Biochemistry and Behavior. 1980; 12: 143-153.

[98] Dalterio SL. Cannabinoid exposure: effects on development. Neurobehavioral Toxicology and Teratology. 1986; 8: 345-352.

[99] Mokler D, Robinson S, Johnson J, Hong J, Rosecrans J. Neonatal administration of delta-9-tetrahydrocannabinol (THC) alters the neurochemical response to stress in the adult Fischer-344 rat. Neurotoxicology and Teratology. 1987; 9: 321-327.

[100] Vela G, Fuentes J, Bonnin A, Ferna'ndez-Ruiz J, Ruiz-Gayo M. Perinatal exposure to $\Delta$ 9-tetrahydrocannabinol $(\Delta 9$-THC) leads to changes in opioid-related behavioral patterns in rats. Brain Research. 1995; 680: 142-147.

[101] Meyer HC, Lee FS, Gee DG. The Role of the Endocannabinoid System and Genetic Variation in Adolescent Brain Development. Neuropsychopharmacology. 2018; 43: 21-33.

[102] Mechoulam R, Parker LA. The Endocannabinoid System and the Brain. Annual Review of Psychology. 2013; 64: 21-47.

[103] Parsons LH, Hurd YL. Endocannabinoid signalling in reward and addiction. Nature Reviews Neuroscience. 2015; 16: 579594.

[104] Malone DT, Hill MN, Rubino T. Adolescent cannabis use and psychosis: epidemiology and neurodevelopmental models. British Journal of Pharmacology. 2010; 160: 511-522.

[105] Scherma M, Qvist JS, Asok A, Huang SC, Masia P, Deidda M, et al. Cannabinoid exposure in rat adolescence reprograms the initial behavioral, molecular, and epigenetic response to cocaine. Proceedings of the National Academy of Sciences. 2020; 117: 9991-10002.

[106] Fergusson DM, Boden JM, Horwood LJ. Cannabis use and other illicit drug use: testing the cannabis gateway hypothesis. Addiction. 2006; 101: 556-569.

[107] Corsi DJ, Donelle J, Sucha E, Hawken S, Hsu H, El-Chaâr D, et al. Maternal cannabis use in pregnancy and child neurodevelopmental outcomes. Nature Medicine. 2020; 26: 1536-1540.

[108] van Gelder MMHJ, Reefhuis J, Caton AR, Werler MM, Druschel CM, Roeleveld N. Characteristics of pregnant illicit drug users and associations between cannabis use and perinatal out- come in a population-based study. Drug and Alcohol Dependence. 2010; 109: 243-247.

[109] Krishnamoorthy D, Kaminer Y. The Effects of Prenatal Exposure to Marijuana on Early Childhood Development: A Systematic Literature Review. Cannabis. 2020; 3: 11-18.

[110] Fonseca BM, Correia-da-Silva G, Almada M, Costa MA, Teixeira NA. The Endocannabinoid System in the Postimplantation Period: a Role during Decidualization and Placentation. International Journal of Endocrinology. 2013; 2013: 1-11.

[111] Hurd Y, Wang X, Anderson V, Beck O, Minkoff H, Dowedwards D. Marijuana impairs growth in mid-gestation fetuses. Neurotoxicology and Teratology. 2005; 27: 221-229.

[112] Fried PA. Cannabis use during pregnancy: its effects on offspring from birth to young adulthood. Alcohol Drugs and Medication in Pregnancy. 2011; 153-168.

[113] Smithers LG, Lynch JW, Yang S, Dahhou M, Kramer MS. Impact of Neonatal Growth on IQ and Behavior at Early School Age. Pediatrics. 2013; 132: e53-e60.

[114] Aliferis KA, Bernard-Perron D. Cannabinomics: Application of Metabolomics in Cannabis (Cannabis sativa L.) Research and Development. Frontiers in Plant Science. 2020; 11: 554.

[115] Jung J, Meyer MR, Maurer HH, Neusüss C, Weinmann W, Auwärter V. Studies on the metabolism of the Delta9tetrahydrocannabinol precursor Delta9-tetrahydrocannabinolic acid A (Delta9-THCA-A) in rat using LC-MS/MS, LC-QTOF MS and GC-MS techniques. Journal of Mass Spectrometry. 2009; 44: 1423-1433.

[116] Sawler J, Stout JM, Gardner KM, Hudson D, Vidmar J, Butler $\mathrm{L}$, et al. The Genetic Structure of Marijuana and Hemp. PLoS ONE. 2015; 10: e0133292.

[117] Compton WM, Han B, Jones CM, Blanco C. Cannabis use disorders among adults in the United States during a time of increasing use of cannabis. Drug and Alcohol Dependence. 2019; 204: 107468.

[118] Han B, Compton WM, Blanco C, Jones CM. Time since first cannabis use and 12-month prevalence of cannabis use disorder among youth and emerging adults in the United States. Addiction. 2019; 114: 698-707.

[119] Shi Y, Zhu B, Liang D. The associations between prenatal cannabis use disorder and neonatal outcomes. Addiction. 2021; 116: 3069-3079.

[120] Christina Orlovsky. Cannabis Use Disorder: Know the Signs. 2021. Available at: www.psycom.net/cannabis-use-disorder (Accessed: 7 December 2021).

[121] Jason Patel, Raman Marwaha. Cannabis Use Disorder. 2021. Available at: https://www.ncbi.nlm.nih.gov/books/NBK 538131/ (Accessed: 7 December 2021).

[122] Pasman JA, Verweij KJH, Gerring Z, Stringer S, SanchezRoige S, Treur JL, et al. GWAS of lifetime cannabis use reveals new risk loci, genetic overlap with psychiatric traits, and a causal influence of schizophrenia. Nature Neuroscience. 2018; 21: 1161-1170.

[123] Morris J, Bailey MES, Baldassarre D, Cullen B, de Faire U, Ferguson A, et al. Genetic variation in CADM2 as a link between psychological traits and obesity. Scientific Reports. 2019; 9: 7339.

[124] Agrawal A, Lynskey MT, Bucholz KK, Martin NG, Madden PAF, Heath AC. Contrasting models of genetic co-morbidity for cannabis and other illicit drugs in adult Australian twins. Psychological Medicine. 2007; 37: 49-60.

[125] Agrawal A, Lynskey MT. Candidate genes for cannabis use disorders: findings, challenges and directions. Addiction. 2009; 104: 518-532.

[126] Hopfer CJ, Young SE, Purcell S, Crowley TJ, Stallings MC, Corley RP, et al. Cannabis receptor haplotype associated with fewer cannabis dependence symptoms in adolescents. American 
Journal of Medical Genetics Part B. 2006; 141: 895-901.

[127] Haughey HM, Marshall E, Schacht JP, Louis A, Hutchison KE. Marijuana withdrawal and craving: influence of the cannabinoid receptor 1 (CNR1) and fatty acid amide hydrolase (FAAH) genes. Addiction. 2008; 103: 1678-1686.

[128] Filbey FM, Schacht JP, Myers US, Chavez RS, Hutchison KE. Individual and Additive Effects of the CNR1 and FAAH Genes on Brain Response to Marijuana Cues. Neuropsychopharmacology. 2010; 35: 967-975.

[129] Carey CE, Agrawal A, Zhang B, Conley ED, Degenhardt L, Heath AC, et al. Monoacylglycerol lipase (MGLL) polymorphism rs604300 interacts with childhood adversity to predict cannabis dependence symptoms and amygdala habituation: Evidence from an endocannabinoid system-level analysis. Journal of Abnormal Psychology. 2015; 124: 860-877.

[130] Arias Horcajadas F, Dávila Píriz JR, Parra González A, Sánchez Romero S, Sánchez-Morla E, Ampuero Sánchez I, et al. Cannabinoid receptor type 2 gene is associated with comorbidity of schizophrenia and cannabis dependence and fatty acid amide hydrolase gene is associated with cannabis dependence in the Spanish population. Adicciones. 2021. (in press)

[131] Demontis D, Rajagopal VM, Thorgeirsson TE, Als TD, Grove $\mathrm{J}$, Leppälä K, et al. Genome-wide association study implicates CHRNA2 in cannabis use disorder. Nature Neuroscience. 2019; 22: 1066-1074

[132] Johnson EC, Demontis D, Thorgeirsson TE, Walters RK, Polimanti R, Hatoum AS, et al. A large-scale genome-wide association study meta-analysis of cannabis use disorder. The Lancet Psychiatry. 2020; 7: 1032-1045.

[133] Denny JC. Chapter 13: Mining electronic health records in the genomics era. PLoS Computational Biology. 2012; 8: e1002823.

[134] Gottesman O, Kuivaniemi H, Tromp G, Faucett WA, Li R, Manolio TA, et al. The Electronic Medical Records and Genomics (eMERGE) Network: past, present, and future. Genetics in Medicine. 2013; 15: 761-771.

[135] Szutorisz H, Hurd YL. Epigenetic Effects of Cannabis Exposure. Biological Psychiatry. 2016; 79: 586-594.

[136] Smith A, Kaufman F, Sandy MS, Cardenas A. Cannabis Exposure during Critical Windows of Development: Epigenetic and Molecular Pathways Implicated in Neuropsychiatric Disease. Current Environmental Health Reports. 2020; 7: 325-342.

[137] Garrido N, Cruz F, Egea RR, Simon C, Sadler-Riggleman I, Beck D, et al. Sperm DNA methylation epimutation biomarker for paternal offspring autism susceptibility. Clinical Epigenetics. 2021; 13: 6

[138] Slotkin TA, Skavicus S, Levin ED, Seidler FJ. Paternal 49 Tetrahydrocannabinol Exposure Prior to Mating Elicits Deficits in Cholinergic Synaptic Function in the Offspring. Toxicological Sciences. 2020; 174: 210-217.

[139] Slotkin TA, Levin ED, Seidler FJ. Paternal Cannabis Exposure Prior to Mating, but not $\Delta 9$-Tetrahydrocannabinol, Elicits Deficits in Dopaminergic Synaptic Activity in the Offspring. Toxicological Sciences. 2021; 184: 252-264.

[140] Jayanthi S, Buie S, Moore S, Herning RI, Better W, Wil- son NM, et al. Heavy marijuana users show increased serum apolipoprotein C-III levels: evidence from proteomic analyses. Molecular Psychiatry. 2010; 15: 101-112.

[141] Hinckley JD, Saba L, Raymond K, Bartels K, Klawitter $\mathrm{J}$, Christians U, et al. An Approach to Biomarker Discovery of Cannabis Use Utilizing Proteomic, Metabolomic, and Lipidomic Analyses. Cannabis and Cannabinoid Research. 2020. (in press)

[142] Nedumaran B, Rudra P, Gaydos J, Kumar S, Meacham RB, Burnham EL, et al. Impact of Regular Cannabis Use on Biomarkers of Lower Urinary Tract Function. Urology. 2017; 109: 223.e9-223.e16.

[143] Happyana N, Kayser O. Monitoring Metabolite Profiles of Cannabis sativa L. Trichomes during Flowering Period Using 1H NMR-Based Metabolomics and Real-Time PCR. Planta Medica. 2016; 82: 1217-1223.

[144] Sharma P, Murthy P, Bharath MM. Chemistry, metabolism, and toxicology of cannabis: clinical implications. Iranian Journal of Psychiatry. 2012; 7: 149-156.

[145] Miller IJ, Peters SR, Overmyer KA, Paulson BR, Westphall MS, Coon JJ. Real-time health monitoring through urine metabolomics. NPJ Digital Medicine. 2019; 2: 109

[146] Trabado S, Al-Salameh A, Croixmarie V, Masson P, Corruble E, Fève B, et al. The human plasma-metabolome: Reference values in 800 French healthy volunteers; impact of cholesterol, gender and age. PLoS ONE. 2017; 12: e0173615.

[147] Psychogios N, Hau DD, Peng J, Guo AC, Mandal R, Bouatra S, et al. The human serum metabolome. PLoS ONE. 2011; 6: e16957.

[148] Centers for Disease Control and Prevention. Exposome and Exposomics. 2014.Available at: www.cdc.gov/niosh/topics/expos ome/default.html (Accessed: 7 December 2021).

[149] Radhakrishnan R. 20. ELUCIDATING The LINK Between CANNABIS USE And PSYCHOSIS: From The EXPOSOME And PHENOME To The EPIGENOME And RECEPTOME. Schizophrenia Bulletin. 2019; 45: S121-S121.

[150] Cicero TJ, Ellis MS, Kasper ZA. Polysubstance Use: a Broader Understanding of Substance Use during the Opioid Crisis. American Journal of Public Health. 2020; 110: 244-250.

[151] Lactation Mudpa. Committee Opinion No. 722, American College of Obstetricians and Gynecologists. Obstetrics \& Gynecology. 2017.

[152] Sarrafpour S, Urits I, Powell J, Nguyen D, Callan J, Orhurhu V, et al. Considerations and Implications of Cannabidiol Use during Pregnancy. Current Pain and Headache Reports. 2020; 24: 38

[153] MacDuffie KE, Kleinhans NM, Stout K, Wilfond BS. Protection Versus Progress: the Challenge of Research on Cannabis Use during Pregnancy. Pediatrics. 2020; 146: S93-S98.

[154] Wang H, Rolls ET, Du X, Du J, Yang D, Li J, et al. Cheng and J. Feng: Severe nausea and vomiting in pregnancy: psychiatric and cognitive problems and brain structure in children. BMC Medicine. 2020; 18: 228.

[155] Ladegard K, Thurstone C, Rylander M. Marijuana Legalization and Youth. Pediatrics. 2020; 145: S165-S174. 